\title{
A ten-year global record of absorbing aerosols above clouds from OMI's near-UV observations
}

Conference Paper · April 2016

CITATION

1

3 authors:

Hiren Jethva

NASA

56 PUBLICATIONS 544 CITATIONS

SEE PROFILE

Changwoo Ahn

Science Systems and Applications, Inc.

50 PUBLICATIONS 668 CITATIONS

SEE PROFILE
READS

52

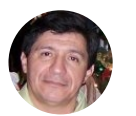

Omar Torres

NASA

244 PUBLICATIONS $\quad \mathbf{1 1 , 8 9 4}$ CITATIONS

SEE PROFILE

All content following this page was uploaded by Hiren Jethva on 11 May 2016. 


\title{
A ten-year global record of absorbing aerosols above clouds from OMI's near-UV observations \\ Hiren Jethva, $^{\mathrm{a}, \mathrm{b}}$, Omar Torres ${ }^{\mathrm{b}}$, Changwoo Ahn ${ }^{\mathrm{c}}$ \\ ${ }^{a}$ Universities Space Research Association, 7178 Columbia Gateway Drive, Columbia, MD 21046, USA \\ bASA Goddard Space Flight Center, Earth Science Division, Code 614, Greenbelt, MD 20771, USA \\ 'Science Systems and Applications, Inc., 10210 Greenbelt Rd, Lanham, MD 20706 USA
}

\begin{abstract}
Aerosol-cloud interaction continues to be one of the leading uncertain components of climate models, primarily due to the lack of an adequate knowledge of the complex microphysical and radiative processes associated with the aerosolcloud system. The situations when aerosols and clouds are found in the same atmospheric column, for instance, when light-absorbing aerosols such as biomass burning generated carbonaceous particles or wind-blown dust overlay low-level cloud decks, are commonly found over several regional of the world. Contrary to the cloud-free scenario over dark surface, for which aerosols are known to produce a net cooling effect (negative radiative forcing) on climate, the overlapping situation of absorbing aerosols over cloud can potentially exert a significant level of atmospheric absorption and produces a positive radiative forcing at top-of-atmosphere. The magnitude of direct radiative effects of aerosols above cloud depends directly on the aerosol loading, microphysical-optical properties of the aerosol layer and the underlying cloud deck, and geometric cloud fraction. We help in addressing this problem by introducing a novel product of optical depth of absorbing aerosols above clouds retrieved from near-UV observations made by the Ozone Monitoring Instrument (OMI) on board NASA's Aura platform. The presence of absorbing aerosols above cloud reduces the upwelling radiation reflected by cloud and produces a strong 'color ratio' effect in the near-UV region, which can be unambiguously detected in the OMI measurements. Physically based on this effect, the OMACA algorithm retrieves the optical depths of aerosols and clouds simultaneously under a prescribed state of atmosphere. The algorithm architecture and results from a ten-year global record including global climatology of frequency of occurrence and above-cloud aerosol optical depth, and a discussion on related future field campaigns are presented.
\end{abstract}

Keywords: aerosols above clouds, aerosol absorption, color ratio, Ozone Monitoring Instrument, OMACA

\section{INTRODUCTION}

Aerosol-cloud interaction continues to be one of the major uncertain components of climate models, primarily due to the lack of an adequate knowledge of the complex microphysical and radiative processes associated with the aerosol-cloud system [1]. One important aspect of the problem is when aerosol and clouds are found in the same atmospheric column, for instance, when light-absorbing aerosols such as biomass burning generated carbonaceous particles and wind-blown dust overlay low-level cloud decks. Contrary to the cloud-free scenario over dark surface, for which aerosols are known to produce a net cooling effect (negative radiative forcing) on climate, the overlapping situation of absorbing aerosols over cloud can potentially exert a significant level of atmospheric absorption and produces a positive radiative forcing at top-of-atmosphere (TOA) [2], [3]. The magnitude of direct radiative effects of aerosols above cloud depends directly on the aerosol loading, microphysical-optical properties of the aerosol layer and the underlying cloud deck [4] as well as geometric cloud fraction [3]. The resultant aerosol-driven atmospheric heating can have a great influence on the atmospheric stability, cloud formation and lifetime, and the hydrological cycle. Therefore, in order to quantify aerosol loading above cloud and its resultant effects on climate, it is imperative that a measurement-based global database be made available to community.

Ground-based sunphotometer cannot measure aerosol loading above cloud; however satellite-based passive and active sensors can see the atmospheric column above cloud. Conventional satellite retrievals have provided a global 
distribution of aerosols over only cloud-free regions which severely limit our understanding of the aerosol effects on cloud radiative forcing and microphysical properties.

Light absorbing aerosols such as carbonaceous aerosols and dust particles exhibit strong wavelength dependence in absorption, particularly in the UV region of the spectrum. On the other hand, clouds show less or no spectral dependence in reflectance when measured from space. When absorbing aerosols overlay cloud deck, the spectral contrast in the UV is further enhanced which produces a strong 'color ratio' effect in the TOA reflectance measurements. It is shown in [5] that under a prescribed set of atmospheric and surface condition; the measurements of 'color ratio' between 354 and 388 $\mathrm{nm}$ channels and reflectance at $388 \mathrm{~nm}$ made by the Ozone Monitoring Instrument (OMI) on board NASA's Aura platform can be related to a pair of above-cloud aerosol optical depth (ACAOD) and aerosol-corrected cloud optical depth (COD). In this paper, we apply this 'color ratio' technique developed by [5] to the 10-year global near-UV observations made by OMI in order to produce a global product of aerosols above cloud. Section 2 describes different components of the global algorithm; section 3 discuss the results of analysis of the global frequency of occurrence of aerosols above clouds; section 4 presents the global climatology of ACAOD; in section 5 a brief discussion on the upcoming high-profile field campaigns that are aimed to characterize aerosols above cloud over the southeastern Atlantic Ocean; and section 6 summarizes the work presented in this paper.

\section{ALGORITHM DESCRIPTION}

\subsection{Physical Basis}

The presence of absorbing aerosols such as carbonaceous aerosols generated from biomass burning and windblown dust particles above cloud decks reduces the amount of upwelling ultraviolet (UV), visible (VIS), and shortwave infrared radiation reaching the top of atmosphere (TOA). This effect is often referred to as "cloud darkening" which can be seen by eye in images and quantitatively in the spectral reflectance measurements made by passive sensors such as OMI. The UV Aerosol Index (UV-AI) measured by OMI is an excellent indicator of the presence of absorbing aerosols in the clear [6] as well as cloudy atmosphere [5]. When the elevated layers of absorbing aerosols overlay low-level cloud deck, the spectral contrast between the TOA measurements in the two near-UV channel (354 and $388 \mathrm{~nm}$ ) further increases, which leads to larger magnitudes in UV-AI. Radiative transfer simulation shows that under a set of prescribed atmosphere, the reduction in the spectral reflectance and color ratio (or UV-AI) between a pair of wavelengths is a function of both aerosol and cloud optical depth. This forms the physical basis of the simultaneous retrieval of above-cloud aerosol optical depth (ACAOD) and aerosol-corrected cloud optical depth (COD) from OMI observations. Since the technique is physically based on the spectral contrast in the TOA measurements, it is formally named as 'color ratio' method. The sensitivity study, technique, and its application to different case studies of carbonaceous aerosols above the cloud over the southeastern Atlantic Ocean are documented in [5].

\subsection{Inputs and Ancillary Dataset}

We use OMI Level-1b calibrated and geo-located radiance measurements at 354 and $388 \mathrm{~nm}$ as input to the algorithm, formally named as OMACA (OMI Above-Cloud Aerosols). In order to retrieve ACAOD, OMACA uses a set of ancillary dataset and assumes specific aerosol models. For the representation of aerosol vertical profile, we use a 30month climatology of aerosol layer height (ALH) dataset derived using combined and co-located measurements of CALIOP vertical back-scatter and OMI UV-AI. The aerosol profile follows a Gaussian distribution around mean ALH given by the CALIOP/OMI dataset. We use recently derived OMI-based near-UV surface albedo database to characterize the surface. Aerosol type identification scheme is adopted from the operational clear-sky OMI/OMAERUV two-channel algorithm. The scheme uses Aura/OMI UV-AI and Aqua/AIRS retrievals of Carbon Monoxide (CO) to distinguish carbonaceous aerosols and dust particles, which subsequently used to select either smoke or dust model depending upon the magnitudes of $\mathrm{CO}$. Above described components of OMACA algorithm are essentially identical to the ones adopted in the operational clear-sky OMI/OMAERUV two-channel algorithm [7]. For the assumption on aerosol single-scattering albedo (SSA) above cloud, we take advantage of the cloud-free standard OMAERUV retrievals of SSA. The whole globe is divided in to 11 discrete regions based upon expected patterns of absorbing aerosols above cloud inferred from the frequency of occurrence analysis (presented in section 3). For each region and for each day of observation, the representative value of above-cloud SSA was derived using the UV-AI weighted clear-sky SSA retrieval for all 11 discrete regions. Any observation of aerosols above cloud found outside the boundaries of these 11 regions was assigned a fixed SSA of 0.9 . 
A Global OMI Above-cloud Aerosol (ACA) Algorithm - OMACA

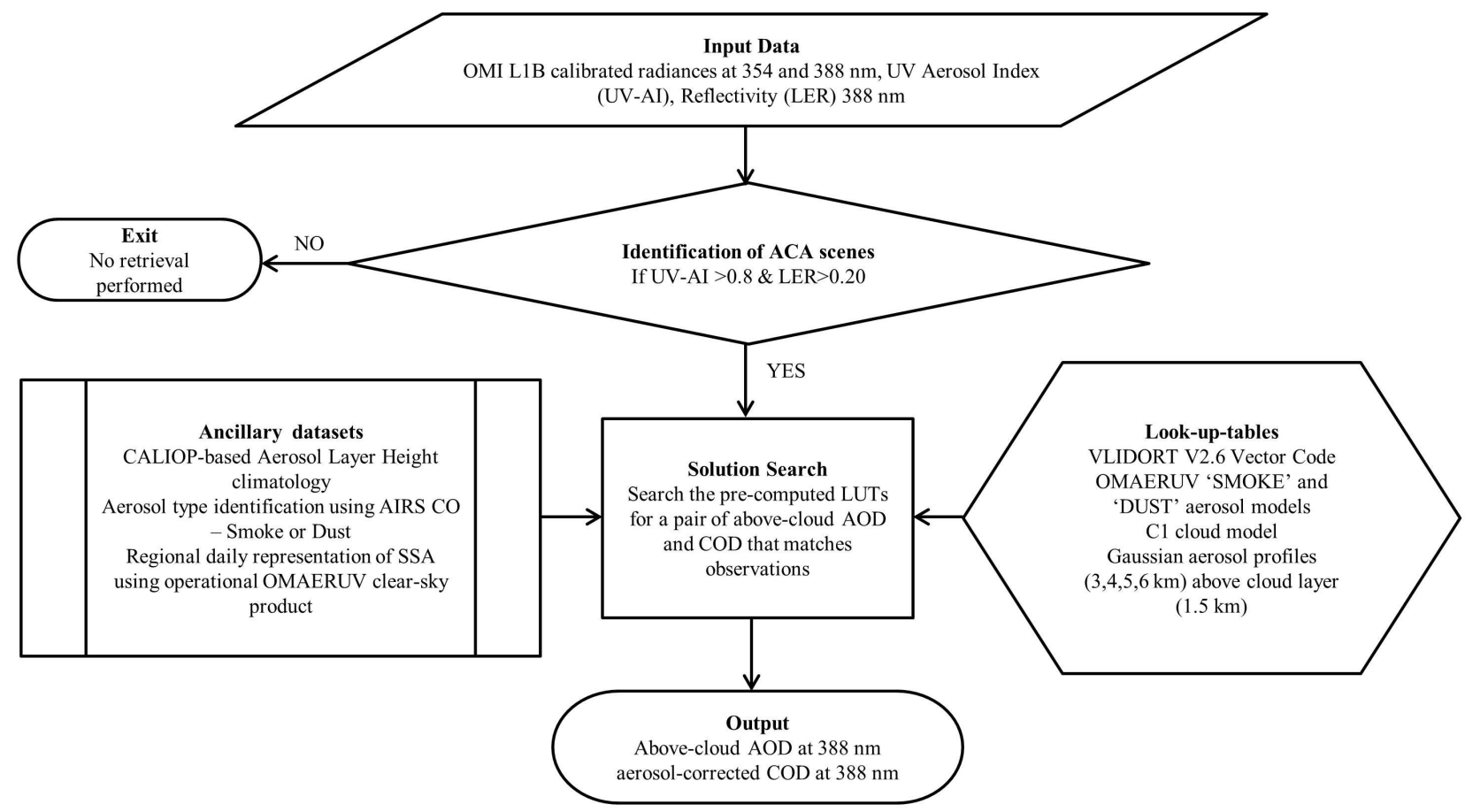

Figure 1 Flow chart of the OMACA algorithm.

\subsection{Look-up-tables}

The OMACA is essentially a look-up-table (LUTs) based algorithm. To generated LUTs, we employ the vector discrete ordinate radiative transfer model VLIDORT [8]. This code offers full linearization ability with outputs of the Stoke vector for arbitrary viewing geometry and optical thickness of aerosols and cloud. The model results have been compared and benchmarked against the established results in the literature and also used in recent studies of retrieval of ACAOD from space-based sensors [5][9]. Clouds are assumed to be liquid in phase and follow standard C1 size distribution. Aerosol size distribution is assumed to follow bi-modal log-normal distribution with parameters adopted from the standard OMAERUV aerosol models.

LUTs were generated for carbonaceous and dust aerosol models, each aerosol type consists of seven discrete aerosol SSA (388 nm) ranging from 0.75 to 1.00 , for the 354- and 388-nm wavelengths for total of seven values or nodal points in $\operatorname{ACAOD}(0.0,0.1,0.5,1.0,2.5,4.0$, and 6.0 at $500 \mathrm{~nm})$ and eight nodal values in $\operatorname{COD}(0,2,5,10,20,30,40$, and 50) at different geometries of solar zenith angle $\left(0^{\circ}, 20^{\circ}, 40^{\circ}, 60^{\circ}, 66^{\circ}, 72^{\circ}, 80^{\circ}\right)$, view zenith angle $\left(0^{\circ}, 12^{\circ}, 18^{\circ}, 26^{\circ}, 32^{\circ}, 36^{\circ}, 40^{\circ}, 46^{\circ}, 50^{\circ}, 54^{\circ}, 56^{\circ}, 60^{\circ}, 66^{\circ}, 72^{\circ}\right)$, and relative azimuth angle $\left(0^{\circ}-150^{\circ}\right.$ in step of $30^{\circ}$, $\left.160^{\circ}, 165^{\circ}, 170^{\circ}, 175^{\circ}, 180^{\circ}\right)$. The simulations were carried out for two surface pressure levels $(1013.25 \mathrm{hPa}, 800 \mathrm{hPa})$ and for four different ALH, i.e., 3, 4, 5, $6 \mathrm{~km}$ referenced at respective surface pressure levels.

The LUT radiances interpolated at observed geometry, pressure level, aerosol layer height, and single-scattering albedo now matched with the OMI-observed radiance in 2D retrieval domain (ratio of radiances (354/388) versus radiance at $388 \mathrm{~nm}$ ) in order to find a pair of ACAOD and COD at $388 \mathrm{~nm}$. The retrieved values at $388 \mathrm{~nm}$ were converted to 354 $\mathrm{nm}$ and $500 \mathrm{~nm}$ wavelengths based on the spectral dependence of extinction associated with the assumed model. Figure 1 illustrates the flow chart of the OMACA algorithm.

\subsection{Algorithm Quality Flags}

Each qualified OMI retrieval of the above-cloud aerosols has been assigned with an algorithm quality flag. While pixels with larger magnitudes of UV-AI and LER388 are expected to be the best retrieval, lower magnitudes of both parameters might be of inferior quality due to less confidence in the detection of either overcast pixels (lower LER388) or the 
presence of absorbing aerosols above cloud (lower UV-AI). Table 1 describes algorithm quality flags assigned to the each valid retrieval. In this paper, we use only 'best' quality retrieval (Quality Flag $=0$ ) for the analysis.

Using above-described OMACA algorithm, a ten-year global record of ACAOD has been derived from OMI's near-UV observations whose results are presented in the rest of the paper. Table 1 Description of OMACA algorithm quality flags

\section{FREQUENCY OF OCCURRENCE OF ABSORBING AEROSOLS ABOVE CLOUDS}

The global climate impact of absorbing aerosols above cloud depend on the total aerosol loading above cloud, the microphysical and optical properties of aerosols and underlying cloud deck as well as the spatial and temporal extent of the aerosol-cloud overlap scenes. We have carried out a global frequency of occurrence of absorbing aerosols above cloud (FOOACA) in order to ...We use two parameters measured by OMI, namely LER388 and UV-AI, to identify the number of cloudy pixels (LER388 $>0.25$ ) and ACA pixels (LER388 $>0.25 \&$ UV-AI $>1.3$ ). FOOACA is referenced to the cloudy-sky observations and defined as the ratio of number of days with ACA condition to the number of days with

Table 1 Description of OMACA Algorithm Quality Flags

\begin{tabular}{|c|c|c|}
\hline $\begin{array}{c}\text { Algorithm Quality } \\
\text { Flags }\end{array}$ & Observation Conditions & Description \\
\hline 0 & UV-AI (Mie) $>1.3 \&$ LER388 $>0.25$ & Best quality retrievals \\
\hline 1 & 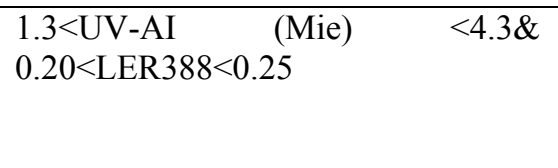 & $\begin{array}{l}\text { Less confidence on the } \\
\text { detection of total overcast } \\
\text { pixels (Use of high-res sensors } \\
\text { is recommended) }\end{array}$ \\
\hline 2 & $0.8<$ UV-AI (Mie) $<1.3 \&$ \& LER $>0.25$ & $\begin{array}{l}\text { Less confidence on the } \\
\text { detection of aerosols above } \\
\text { cloud }\end{array}$ \\
\hline 3 & 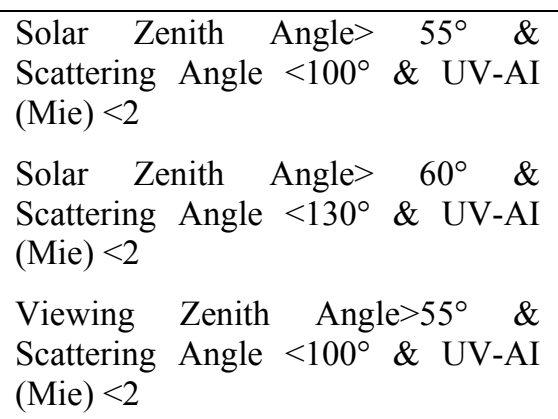 & Geometry-related artifacts \\
\hline
\end{tabular}

cloud-only condition. The FOOACA is derived globally on a monthly scale at grid size of $0.5^{\circ}$ by $0.5^{\circ}$. Since mid-2007, OMI observations have been affected by a likely external obstruction that perturbs both the measured solar flux and Earth radiance. This obstruction affecting the quality of radiance at all wavelengths for a particular viewing direction is referred to as "row anomaly" since the viewing geometry is associated with the row numbers on the charge-coupled device detectors. The row anomaly issue was detected first time in mid-2007 with a couple of rows which over the period of operation expanded to other rows in 2008 and later. At present, about half of the total 60 rows across the track are identified and flagged as row anomaly affected positions for which no physical retrievals are being performed. The details about this issue can be found at http://www.knmi.nl/omi/research/product/rowanomaly-background.php.

It is concluded in [10] that in order to derive a meaningful trend in the global FOOACA only those rows or positions of OMI instrument should be used that are largely unaffected by the row anomaly issue throughout the OMI operation 

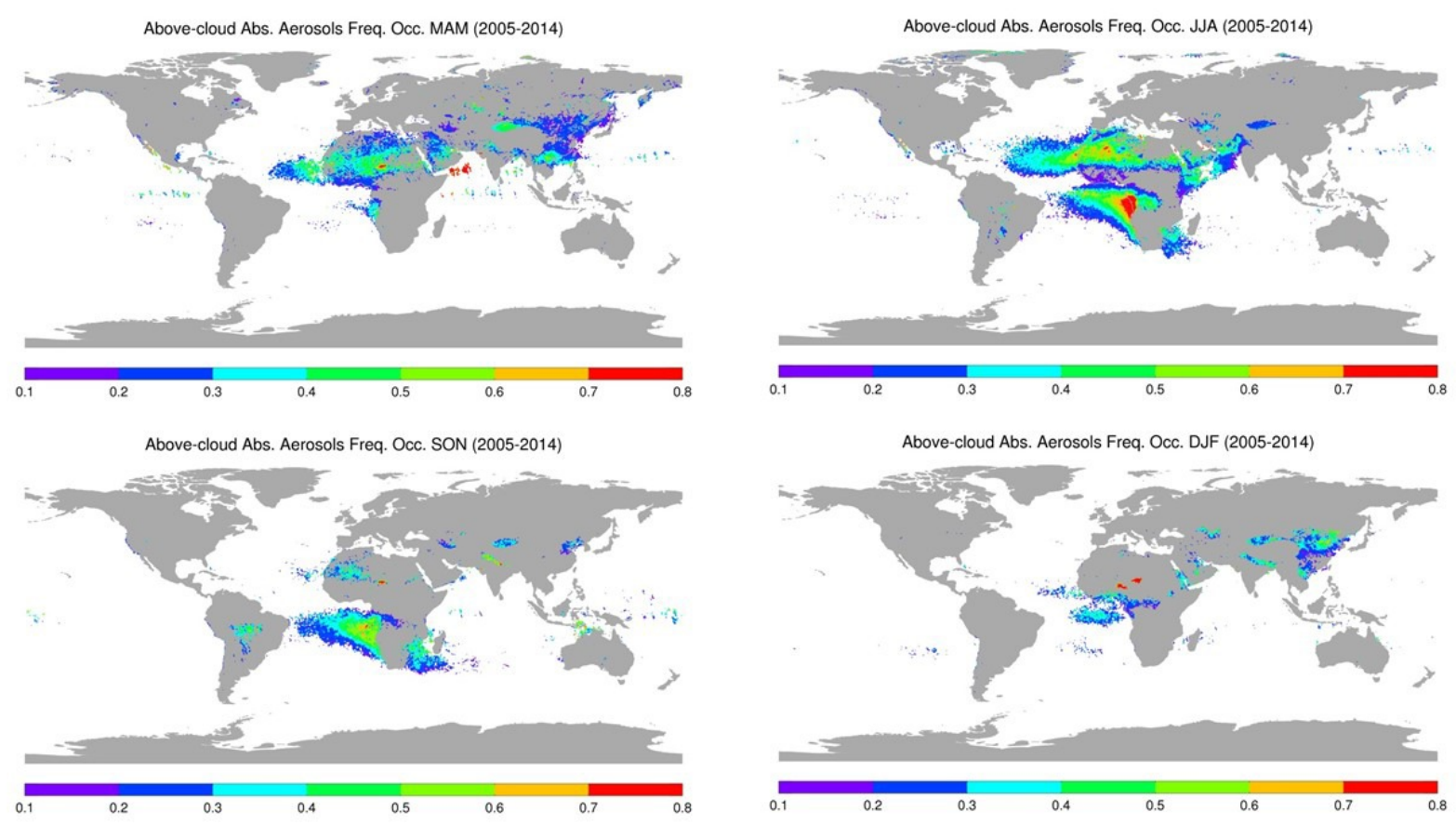

Figure 2 Seasonal frequency of occurrence of absorbing aerosols above cloud derived from OMI's near-UV observations. Acronyms: MAM: March-April-May; JJA: June-July-August; SON: September-October-November; DJF: December-January-February

period (2004 to present). This is because UV-AI has a dependency on scan angle in which the left side of the scan shows higher values than its right side counterpart. Since OMI lost most rows on the right side of the scan post-2007 operation due to row anomaly, the remaining rows on left side of the scan introduces a positive shift in the absolute values of UVAI which leads to an overall positive trend in the FOOACA. Therefore, in the present analysis we use only those rows of OMI (Row \# 1 to 23) that are largely unaffected by the row anomaly issue throughout the OMI operation period.

Figure 2 shows the seasonal FOOACA derived from 10-year record (2005-2014) of OMI following above described method. This analysis reveals several important regions of the world where the overlap of absorbing aerosols over clouds are frequently observed. These regions include southeastern Atlantic Ocean where the smoke transported from the adjacent land region overlie low-level stratocumulus water clouds during July through September, tropical Atlantic Ocean and northern Arabian Sea where dust particles transported from Sahara and Arabian deserts, respectively, overlie low-level water clouds during June through August, South-East Asia where springtime biomass burning sends significant amount of carbonaceous aerosols over widespread cloud deck over southern China. In addition to these regions, the presence of absorbing aerosols over cloud is also observed over northern India and north-east China during northern hemisphere winter. We notice no significant trend in FOOACA, regionally as well as globally, when OMI observations from rows that are free of row anomaly throughout the OMI operation period (2004 to present) were used in the calculations. On the basis of the present findings and also according to the results published in an interactive comment [10], we strongly recommend users to use OMI observations that free of row anomaly throughout the OMI operation (2004 to present) for the trend related analysis.

\section{GLOBAL DISTRIBUTION OF ABOVE-CLOUD AOD}

Figure 3 shows the seasonal climatology of ACAOD $(388 \mathrm{~nm})$ derived from the OMACA algorithm applied to the 10year global record (2005-2014) of OMI's near-UV observations. The magnitude of ACAOD varies from 0.3 to above 0.8 

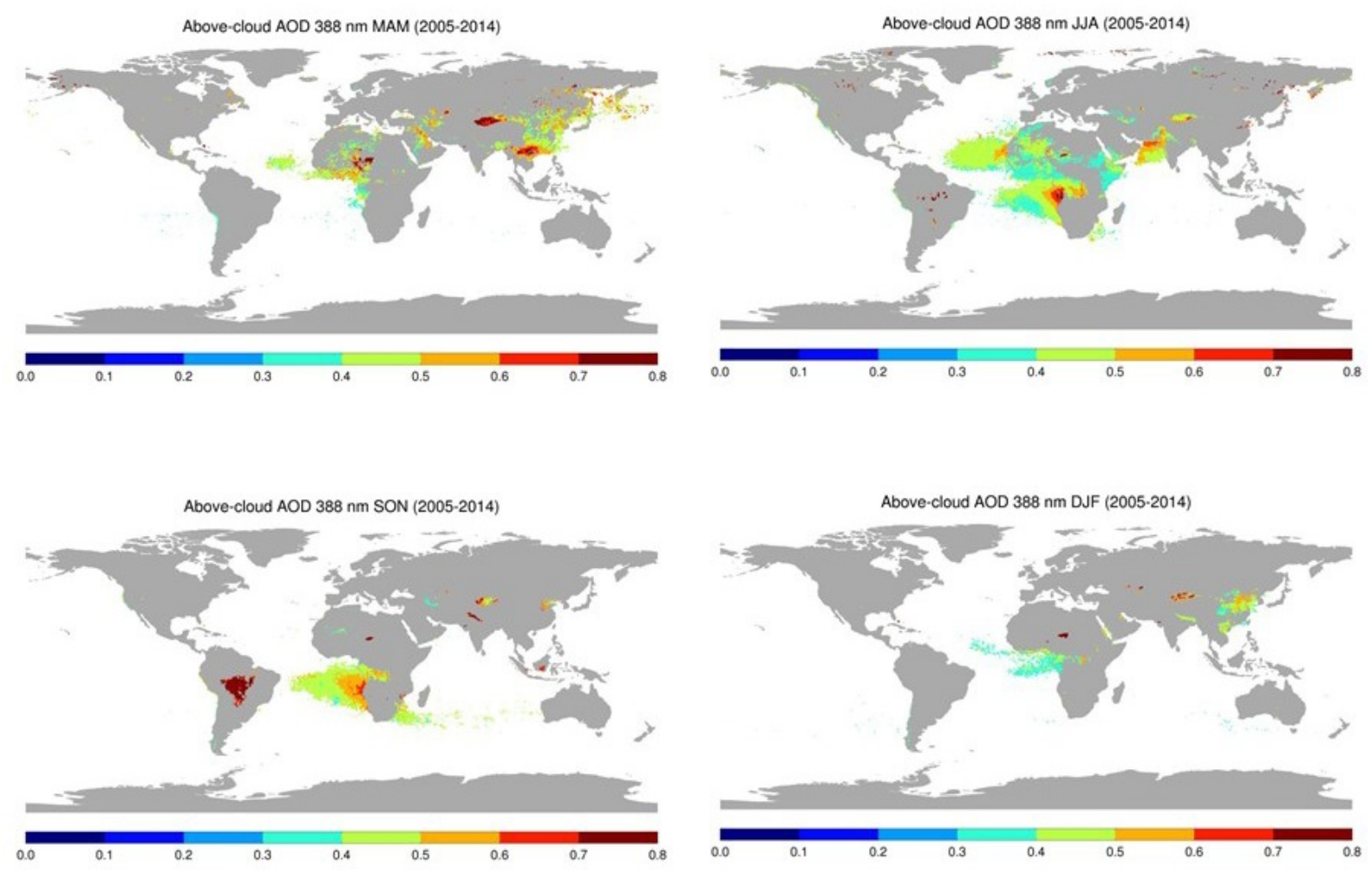

Figure 3 Seasonal climatology maps of above-cloud AOD $(388 \mathrm{~nm})$ derived using OMACA algorithm applied to the 10-year record of OMI's near-UV observations. Acronyms: MAM: March-April-May; JJA: June-July-August; SON: September-October-November; DJF: December-January-February

depending upon region and time of the year. During JJA, a gradient of ACAOD is observed over the southeastern Atlantic Ocean with larger aerosol loading $(>0.8)$ near the coast and in the vicinity of the source biomass burning region.

During the same season, ACAOD in the range 0.4-0.5 is observed over the tropical Atlantic Ocean where dust transport takes place from the Saharan desert. Also a gradient in ACAOD is noted over the northern Arabian Sea owing to dust transport from Arabian region over the low-level cloud deck. During spring (MAM), biomass burning in South-East Asia emits huge amount of carbonaceous aerosols which under the influence of winds are mobilized above the cloud deck over southern China, where OMACA retrieves large values of ACAOD $(>0.8)$. Similarly, wintertime (DJF) biomass burning in the Sahel region sends large amount of smoke particles over the Atlantic Ocean for which the OMACA algorithm retrieves ACAOD in the range 0.3-0.4.

When compared with the operational cloud-free OMI/OMAERUV two-channel AOD retrieval, the above-cloud AOD accounts for about $60 \%-70 \%, 70 \%-80 \%, 40-50 \%$ of total columnar AOD over the southeastern Atlantic Ocean, tropical Atlantic Ocean, and South-East Asia, respectively. It suggests that with OMACA algorithm it becomes possible to observe aerosol loading in the cloudy situation which otherwise is missed in the conventional cloud-free aerosol products. This is an important finding because climatology of aerosol distribution and associated radiative forcing estimated from the cloud-free aerosol product would be incomplete and biased towards clear-sky observations, whereas composite distribution retrieved from clear- and cloud-sky (OMACA) observations would provide an understanding about all-sky aerosol distribution and resultant radiative forcing.

\section{VALIDATION OF ABOVE-CLOUD AOD}

Past field campaigns focused on characterizing aerosol properties in cloud-free regions in order to evaluate and improve satellite-based retrievals, but it left vast cloudy areas unmonitored in terms of the aerosol measurements. Now satellitebased remote sensing techniques using passive sensors, such as from Aura/OMI as presented in this paper, are beginning 
to quantitatively measure aerosol loading above cloud over a large spatial domain; however validation of the these retrievals will remain incomplete without the availability of adequate and accurate airborne measurements.

NASA's ORACLES-ObseRvations of Aerosols above CLouds and their intEractionS (https://espo.nasa.gov/oracles) is an upcoming multi-year field experiment funded by the NASA Earth-Venture Suborbital Program. Beginning in July 2016, the ORACLES experiment intends to make detailed and accurate airborne remote sensing and in situ measurements of the key parameters that govern the cloud-aerosol interaction in the south-east Atlantic Ocean. Owing to the huge abundance of lofted biomass burning aerosols over the semi-permanent marine boundary layer stratocumulus cloud deck, this region serves as a perfect natural laboratory to assess aerosol-cloud-radiation interactions. Note that this is an area with some of the largest inter-model differences in aerosol forcing assessments on the planet. The experiment will employ a suite of sensors including 4STAR and High Spectral Resolution Lidar (HSRL-2) on NASA's P-3B and ER-2 aircrafts, respectively. Both instruments are relevant to the assessment and validation of satellite retrieval of ACAOD.

In parallel with ORACLES, the Cloud Aerosol Radiation Interactions and Forcing: Year 2016 (CLARIFY-2016) campaign with project partners from the UK Met Office and universities will also take place over the same region with deployment of airborne and surface-based instruments in conjunction with satellite observations of aerosols and clouds. Both of these planned high-profile experiments will deliver a wide range of direct and in situ observations of aerosol above clouds to provide a better process-level understanding of aerosol-cloud-radiation interactions over the SE Atlantic. Among the planned measurements, direct AOD and detailed optical and microphysical measurements of aerosols above cloud will be germane for validating and improving satellite-based retrievals. For instance, the microphysical models, in particular the imaginary part of refractive index and SSA, assumed in the satellite-based inversion pose the largest source of uncertainty in the retrieval. Observations from ORACLES and CLARIFY-2016 will challenge and improve these models for achieving better accuracy in the satellite retrieval.

True validation exercises, such as the opportunities to compare satellite retrievals with a high quality airborne instrument are essential components in quantifying the true uncertainties in the space-based retrievals of the aerosols above clouds.

\section{SUMMARY}

We have developed a global aerosol algorithm, formally named as OMACA, to simultaneously derive the columnar optical depth of absorbing aerosols above cloud (ACAOD) and aerosol-corrected cloud optical depth (COD) from Aura/OMI's near-UV observations. The 'color ratio' technique developed by [5] was applied to the OMI observations to deduce a ten-year global record of aerosol loading above cloud. The technique is physically based on the enhanced aerosol absorption above the cloud which can be related to a pair of ACAOD and COD under a prescribed set of assumptions. The algorithm structure is essentially similar to the OMI's two-channel operational cloud-free aerosol algorithm OMAERUV [11].

An analysis of the frequency of occurrence of above-cloud absorbing aerosols reveals several important regions of the world where the overlap of absorbing aerosols and cloud are frequently observed on a monthly to seasonal scales. These regions include southeastern Atlantic Ocean and Southeast Asia, where layers of smoke aerosols produced from agricultural biomass burning overlie low-level stratocumulus cloud deck, tropical Atlantic Ocean and northern Arabian Sea, where dust aerosols transported from Sahara and Arabian deserts, respectively, found over low-level clouds, and northeast Asia where pollution haze mixed with dust particles found to overlie clouds. Globally as well as regionally, no significant trend in the frequency of ACA was noted when only those rows of OMI instrument (Row \# 1 to 23) that are free of row anomaly throughout the OMI operation period (2004 to present) were used in the analysis. The seasonal climatology maps of ACAOD $(388 \mathrm{~nm})$ shows moderate $(0.3-0.5)$ to higher aerosol loading $(>0.8)$ above cloud over these prominent aerosols-cloud overlap regions. When compared with the cloud-free aerosol loading distribution retrieved from OMI/OMAERUV two-channel algorithm, above-cloud AOD represents about $40 \%-70 \%$ of the total columnar loading over different regions.

Conventional aerosol remote sensing algorithms provide distribution of aerosols in the cloud-free areas leaving behind vast cloudy regions unmonitored in terms of the co-presence of aerosols and clouds. To the best of our knowledge, 
OMACA aerosol product is first of its kind dataset that offers quantitative characterization of aerosol loading above cloud on a global scale. Several observational and modelling studies have shown that an overlap of absorbing aerosols above cloud potentially leads to a significant atmospheric warming, which can affect cloud lifetime and hydrological cycle. The magnitudes of these effects depend upon amount of aerosol loading above cloud, cloud brightness (COD), optical and microphysical properties of aerosols and clouds, and cloud fraction. The OMACA aerosol product from OMI presented in this paper offers a crucial missing piece of information of the aerosol loading above cloud that will help us to quantify the radiative effects of aerosols above cloud and its resultant impact on clouds and thus climate. A global above cloud aerosol product, in conjunction with standard cloud-free aerosol products, will provide us with an unprecedented all-sky aerosol distribution from space. This can substantially enhance our knowledge on how aerosols affect cloud radiative forcing and microphysical properties, and aerosol transport.

\section{REFERENCES}

[1] IPCC, 2013: Climate Change 2013: The Physical Science Basis. Contribution of Working Group I to the Fifth Assessment Report of the Intergovernmental Panel on Climate Change [Stocker, T.F., D. Qin, G.-K. Plattner, M. Tignor, S.K. Allen, J. Boschung, A. Nauels, Y. Xia, V. Bex and P.M. Midgley (eds.)]. Cambridge University Press, Cambridge, United Kingdom and New York, NY, USA, 1535 pp (2013)

[2] Keil, A. and Haywood, J. M., "Solar radiative forcing by biomass burning aerosol particles during SAFARI2000: A case study based on measured aerosol and cloud properties," J. Geophys. Res., vol. 108, p. 8467 (2003), doi:10.1029/2002JD002315.

[3] Chand, D. Wood, R., Anderson, T. L., Satheesh, S. K., and Charlson, R. J., "Satellite-derived direct radiative effect of aerosols dependent on cloud cover," Nat. Geosci., vol. 2, pp. 181-184 (2009), doi:10.1038/NGEO437.

[4] Meyer, K., Platnick, S., Oreopoulos, L., and Lee, D., "Estimating the direct radiative effect of absorbing aerosols overlying marine boundary layer clouds in the southeast atlantic using modis and caliop," J. Geophys. Res. Atmos., vol. 118, pp., 4801-4815 (2015), doi:10.1002/jgrd.50449.

[5] Torres, O., Jethva, H., and Bhartia, P. K., "Retrieval of aerosol optical depth above clouds from OMI observations: Sensitivity analysis and case studies," J. Atmos. Sci., vol. 69, pp. 1037-1053 (2012), http://dx.doi.org/10.1175/JASD-11-0130.1.

[6] Torres, O., Bhartia, P. K., Herman, J. R., Ahmad, Z., and Gleason, J., "Derivation of aerosol properties from satellite measurements of backscattered ultraviolet radiation: Theoretical basis", J. Geophys. Res., 103(D14), 17,099-17,110 (1998), doi:10.1029/98JD00900.

[7] Torres, O., Ahn, C., and Chen, Z., "Improvements to the OMI near-UV aerosol algorithm using A-train CALIOP and AIRS observations", Atmos. Meas. Tech., 6, 3257-3270 (2013), doi:10.5194/amt-6-3257-2013.

[8] Spurr, R. J. D., "A linearized pseudo-spherical vector discrete ordinate radiative transfer code for forward model and retrieval studies in multilayer multiple scattering media," J. Quant. Spectrosc. Radiat. Transf., vol. 102, no. 2, pp. 316-342 (2006).

[9] Jethva, H., Torres, O., Remer, L. A., and Bhartia, P. K., "A color ratio method for simultaneous retrieval of aerosol and cloud optical thickness of above-cloud absorbing aerosols from passive sensors: Application to modis measurements," Geoscience and Remote Sensing, IEEE Transactions on, vol. 51, no. 7, pp. 3862-3870 (2013), doi:10.1109/TGRS.2012.2230008.

[10] Jethva, H., "Interactive comment on "Investigating the frequency and trends in global above-cloud aerosol characteristics with CALIOP and OMI" by R. Alfaro-Contreras et al.”, Atmos. Chem. Phys. Discuss., 15, C1488C1496 (2015).

[11] Torres, O., Tanskanen, A., Veihelmann, B., Ahn, C., Braak, R., Bhartia, P. K., Veefkind, P., and Levelt, P., "Aerosols and surface UV products from Ozone Monitoring Instrument observations: An overview", J. Geophys. Res., 112, D24S47 (2007) doi:10.1029/2007JD008809. 